\title{
Accelerated methylene blue (MB) degradation by Fenton reagent exposed to UV or VUV/UV light in an innovative micro photo-reactor
}

\author{
Mengkai Li ${ }^{\mathrm{a}, \mathrm{b}}$, Zhimin Qiang ${ }^{\mathrm{a}}$, Cesar Pulgarin ${ }^{\mathrm{b}}$, John Kiwi ${ }^{\mathrm{b}, *}$ \\ a Key Laboratory of Drinking Water Science and Technology, Research Center for Eco-Environmental Sciences, Chinese Academy of Sciences, 18 Shuang-qing \\ Road, Beijing 100085, China \\ ${ }^{\mathrm{b}}$ Ecole Polytechnique Fédérale de Lausanne, EPFL-SB-ISIC-GPAO, Station 6, CH-1015 Lausanne, Switzerland
}

\section{A R T I C L E I N F O}

\section{Article history:}

Received 5 November 2015

Received in revised form 4 January 2016

Accepted 9 January 2016

Available online 13 January 2016

\section{Keywords:}

Vacuum-UV (VUV)

Photo-Fenton

Micro photo-reactor

Methylene blue

Oxidative radicals

Reaction mechanism

\begin{abstract}
A B S T R A C T
This study presents the accelerated discoloration/degradation of methylene blue (MB) in solution by Fenton reagent under exposure to ultraviolet (UV) or Vacuum-UV/UV (VUV/UV) light in an innovative micro photo-reactor. The MB degradation was kinetically faster when using VUV/UV light at 254/185 nm compared to UV-irradiation at $254 \mathrm{~nm}$. Oxidative radicals produced by the photo-Fenton process were identified with appropriate scavengers. The addition of benzoquinone (BQ) at millimolar (mM) concentrations to $\mathrm{MB}$ solutions precluded completely the $\mathrm{MB}$ photo-induced bleaching, while tert-butanol hindered to a lesser extent the $\mathrm{MB}$ degradation suggesting that $\mathrm{HO}_{2}{ }^{\bullet}$ was the predominant intermediate leading to MB degradation. The VUV/UV micro photo-reactor comprised mercury resonance lines at 185 and $254 \mathrm{~nm}$. The photon percentages absorbed by water were estimated to be $16.8 \%$ at $254 \mathrm{~nm}$ and $78.3 \%$ at $185 \mathrm{~nm}$ by water, while those absorbed by $\mathrm{H}_{2} \mathrm{O}_{2}$ were $0.9 \%$ and $2.2 \%$, correspondingly. The solution parameters affecting the features of $\mathrm{MB}$ degradation, such as $\mathrm{MB}, \mathrm{Fe}$, and $\mathrm{H}_{2} \mathrm{O}_{2}$ concentrations, were explored and reaction mechanism was proposed. The lifetimes of $\bullet{ }^{\circ} \mathrm{H}$ and $\mathrm{HO}_{2} \cdot$ were estimated to be $2 \mathrm{~ns}$ and $0.38 \mathrm{~s}$ under an optimized solution with $0.016 \mathrm{mM} \mathrm{MB}, 0.147 \mathrm{mM} \mathrm{H}_{2} \mathrm{O}_{2}$ and $0.05 \mathrm{mM} \mathrm{Fe}^{3+}$. Moreover, an estimation of the mean free paths of these radicals in solution provided the evidence that it was the radical lifetimes and mean-free paths, not their oxidation potentials that controlled the MB degradation kinetics. This study shows the potential of this VUV/UV assistant photo-Fenton process for the degradation of diluted organic compounds in aqueous solution.
\end{abstract}

(c) 2016 Elsevier B.V. All rights reserved.

\section{Introduction}

In recent decades, several advanced oxidation processes (AOPs) that produce highly oxidative radicals such as $\bullet \mathrm{OH},{ }^{\bullet} \mathrm{OH}, \mathrm{Cl}^{\bullet}$ have been reported and applied in water/wastewater treatments [1-10]. The Fenton/photo-Fenton process has been widely reported for the decontamination of a large range of recalcitrant and/or non-biodegradable pollutants during the treatment of industrial wastewaters [11-16]. Photo-Fenton studies deal with the process driven by UV or visible light irradiation generating oxidative radicals from $\mathrm{Fe}^{3+} / \mathrm{H}_{2} \mathrm{O}_{2}[17-22]$. The main reactions are shown below. The reaction $\mathrm{H}_{2} \mathrm{O}_{2}+\mathrm{hv} \rightarrow 2^{\bullet} \mathrm{OH}$ is not important due to the submillimolar $(\mathrm{mM}) \mathrm{H}_{2} \mathrm{O}_{2}$ concentration used

$\mathrm{Fe}^{2+}+\mathrm{H}_{2} \mathrm{O}_{2} \rightarrow \mathrm{Fe}^{3+}+\cdot \mathrm{OH}+\mathrm{OH}^{-} k_{1}=76 \mathrm{M}^{-1} \mathrm{~s}^{-1}$

\footnotetext{
* Corresponding author.

E-mail address: john.kiwi@epfl.ch (J. Kiwi).
}

$$
\begin{aligned}
& \mathrm{Fe}^{3+}+\mathrm{H}_{2} \mathrm{O}_{2} \rightarrow \mathrm{Fe}^{2+}+\mathrm{HO}_{2} \bullet+\mathrm{H}^{+} k_{2}=2 \times 10^{-2} \mathrm{M}^{-1} \mathrm{~s}^{-1} \\
& \mathrm{Fe}^{3+}+\mathrm{HO}_{2} \bullet \mathrm{Fe}^{2+}+\mathrm{O}_{2}+\mathrm{H}^{+} k_{3}=10^{4} \mathrm{M}^{-1} \mathrm{~s}^{-1} \\
& \mathrm{Fe}^{2+}+\bullet \mathrm{OH}^{2} \rightarrow \mathrm{Fe}^{3+}+\mathrm{OH}^{-} k_{4}=4.3 \times 10^{8} \mathrm{M}^{-1} \mathrm{~s}^{-1} \\
& \mathrm{H}_{2} \mathrm{O}_{2}+\bullet \mathrm{OH} \rightarrow \mathrm{HO}_{2} \cdot+\mathrm{H}_{2} \mathrm{O}_{5}=2.7 \times 10^{7} \\
& \mathrm{Fe}^{3+} / \mathrm{Fe}(\mathrm{III})(\mathrm{OH})^{2+}+\mathrm{h} v \rightarrow \mathrm{Fe}^{2+} / \mathrm{Fe}(\mathrm{II})+\bullet \mathrm{OH}[12,15]
\end{aligned}
$$

UV-light sources in photo-reactors commonly use the $254 \mathrm{~nm}$ low-pressure mercury emission line with a relative high photoelectric conversion efficiency of $\sim 30 \%$ in the UV-range $[23,24]$. Low-pressure mercury lamps are able to generate mercury resonance lines at $254 \mathrm{~nm}$ and $185 \mathrm{~nm}$. The percentage of $185 \mathrm{~nm}$ photons varies between $8 \%$ [25] and 25\% [26] depending on the lamp power and manufacturer. These lamps use synthetic quartz of high purity allowing full transparency for the mercury resonance line at $185 \mathrm{~nm}[25,26]$.

The VUV generates radical and ions in water as reported by several laboratories [27-30]. VUV photolysis of pure liquid water leads to radicals ${ }^{\bullet} \mathrm{OH}, \mathrm{HO}_{2}{ }^{\bullet}, \mathrm{O}_{2}{ }^{\bullet-}, \mathrm{H}^{\bullet}$, and stable species like $\mathrm{H}_{2} \mathrm{O}_{2}$, 
<smiles>CN(C)c1ccc2nc3ccc(=[N+](C)C)cc-3sc2c1</smiles>

Scheme 1. (MB).

$\mathrm{HO}_{2}{ }^{-}, \mathrm{O}_{2}$. In this study the kinetics of photoreactions depends on the molar absorption coefficient of water and of methylene blue $(\mathrm{MB})$ in the UV and VUV region. The degradation by $\mathrm{H}_{2} \mathrm{O}_{2} / \mathrm{UV}$ of $4-$ chlorophenol in a slurry photocatalytic reactor has been reported and the degradation study included modeling of the photocatlytic steps [31]. The degradation of pollutants using $\mathrm{H}_{2} \mathrm{O}_{2} / \mathrm{UV}$ has been reported using some modeling [32,33].

Even though the $\mathrm{H}_{2} \mathrm{O}_{2} / \mathrm{UV}$ process presents similarities with the VUV process, there are substantial differences: $a$ in the $\mathrm{H}_{2} \mathrm{O}_{2} / U V$ process, the photolysis of $\mathrm{H}_{2} \mathrm{O}_{2}$ only generates $\bullet \mathrm{OH}$, whereas in the VUV process, photolysis of water generates ${ }^{\bullet} \mathrm{OH}, \mathrm{H}^{\bullet}$ and $e_{\mathrm{aq}}{ }^{-}$, which modify the observed radical reactions. VUV is able to induce homolysis and ionization of $\mathrm{H}_{2} \mathrm{O}$ at $185 \mathrm{~nm}$, as shown below in Eqs. (7) and (8) [34,35], $\mathrm{b} \mathrm{H}_{2} \mathrm{O}_{2} / \mathrm{UV}$ direct photolysis of many organic compounds can be neglected due to their low molar absorption coefficients since they absorb light $<200 \mathrm{~nm}[3,4]$.

$\mathrm{H}_{2} \mathrm{O}+h v(185 \mathrm{~nm}) \rightarrow \bullet \mathrm{OH}+\mathrm{H}^{\bullet} \Phi=0.33$

$\mathrm{H}_{2} \mathrm{O}+h(185 \mathrm{~nm}) \rightarrow \cdot \mathrm{OH}+\mathrm{H}^{+}+e_{\mathrm{aq}}{ }^{-} \Phi=0.045$

Therefore, the radicals noted by Eqs. (7) and (8) contribute to the oxidative radicals produced by the Fenton/photo-Fenton reagent shown above in Eqs. (1)-(6) leading to MB degradation. Scheme 1 shows the MB structural formula.

The sources of $\bullet \mathrm{OH}$ radicals by the Fenton reagent have been already noted in Eqs. (1), (6)-(8). But $\mathrm{H}_{2} \mathrm{O}_{2}$ by itself as noted in Eqs. (7) and (8) is an additional sources of $\bullet \mathrm{OH}$-radicals. Fig. 1 shows graphically the VUV $185 / 254 \mathrm{~nm}$ mercury lines compared to the UV254 nm mercury resonance line. The molar absorption coefficients of $\mathrm{H}_{2} \mathrm{O}_{2}$ and $\mathrm{Fe}(\mathrm{III})$ increase towards shorter wavelengths molar absorption coefficients of $\mathrm{H}_{2} \mathrm{O}_{2}$ are to low to absorb a significant amount of VUV/UV and UV light at the low molarities used in the photo-reactor. Work of our own group reported Fetransitions in solution the microsecond region, depending on the

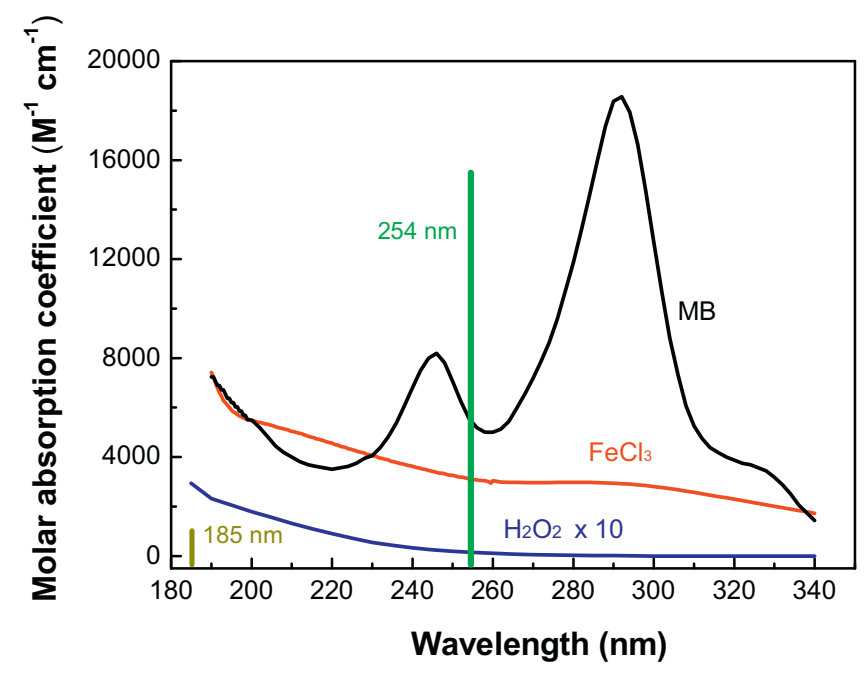

Fig. 1. The absorption spectra of $\mathrm{H}_{2} \mathrm{O}_{2}, \mathrm{FeCl}_{3}$, and $\mathrm{MB}$ and the mercury resonance lines at $254 \mathrm{~nm}$ and $185 \mathrm{~nm}$ of the VUV/UV low pressure mercury lamp used throughout this study. counter-ion, $\mathrm{pH}$ and Fe-species concentration [17]. The Fe (dd) transition depend on the solution parameters and have been reported to occur within the nanosecond/microsecond range $[4,36]$.

Recently, we have reported VUV micro photo-reactor (VMPR) for bench-scale experiments, with mercury resonance lines at $185 / 254 \mathrm{~nm}$ or alternatively presenting the mercury resonance line at 254 [37]. This precludes the very low transmittance in quasicollimated photo-reactors in air, due to the short penetration of VUV light in air of $\sim 50 \mathrm{~mm}$. To solve this problem VUV collimated photo-reactors in a $\mathrm{N}_{2}$ atmosphere have been recently reported $[38,39]$. This study reports for the first time in a detailed, systematic and comprehensive way the effect of $185 / 254 \mathrm{~nm}$ mercury resonance lines and separately the effect of the $185 \mathrm{~nm}$ line on the photo-Fenton mediated MB degradation in solution. This allows reporting the effect due to the radical species and the MB degradation induced by water VUV photolysis in a specific way compared to the effects of the $254 \mathrm{~nm}$ light in photo-Fenton mediated processes. The objective of the present study is to design and test the performance of improved AOP's technologies for water and wastewater treatment.

\section{Experimental}

\subsection{VUV/UV photo-reactor reactor}

The micro VUV/UV photo-reactor (length of $300 \mathrm{~mm}$ ) [37] with double-layers-wall as shown in Supplementary material S1 was used throughout this study. The lamp was cooled by de-ionized water flown through the volume between double-layers-wall and the lamp housing to maintain constant lamp output. The $8 \mathrm{~W}$ coldcathode LP-UV synthetic quartz (arc length $=200 \mathrm{~mm}$, from Haining Xiashi Co., Haining, China) emitted both 185 and 254 nm UV mercury resonance lines to obtain a uniform FR spatial distribution in the axial direction. Synthetic quartz tube was used in the photoreactor transparent to the $185 / 254 \mathrm{~nm}$ light. A Ti-doped silica tube was used for the $254 \mathrm{~nm}$ light experiments. The inner diameter and length of both two tubes were $2 \mathrm{~mm}$ and $100 \mathrm{~mm}$, respectively. Nearly same UV fluence rate (FR) could be obtained in the VUV/UV and UV tubes because both tubes presented a very high $254 \mathrm{~nm}$ transmittance. To obtain a uniform FR spatial distribution, two tubes were placed in the central region in the axial direction of the lamp avoiding the end-lamp regions (i.e., last $50 \mathrm{~mm}$ at each end of the lamp arc) where the FR distribution was observed not to be uniform. Nitrogen was flushed through the inner chamber of the reactor, to eliminate the air-absorption (e.g., $\mathrm{O}_{2}$ ) and maximize the VUV reaching the samples.

\subsection{Chemicals and analytical methods}

Chemicals used for experiments were reagent grade or higher, supplied by Sigma-Aldrich or Fluka. Photo-Fenton experiments were carried out employing ferric chloride $\left(\mathrm{FeCl}_{3}\right)$ and hydrogen peroxide ( $35 \%$ by weight). The $\mathrm{H}_{2} \mathrm{O}_{2}$ concentration during this study was determined by the Titanium (IV) oxy-sulfate $\left(\mathrm{TiOSO}_{4}\right.$ Fluka) method described in Ref. [40].

The MB concentration was determined spectrophotochemically following the peak at $664 \mathrm{~nm}$. The 1,4-benzoquinone (BQ) and tertbutanol (TBA) $[2,3,10]$ were used as the superoxide $\mathrm{O}_{2}{ }^{-}-$and ${ }^{\bullet} \mathrm{OH}$ scavengers, respectively. Milli-Q water (Millipore) was used in all experiments and analytical determinations.

\subsection{Experimental procedures}

The experimental set-up was stabilized for 15 min prior to the re-circulation of the $50 \mathrm{ml}$ sample in the photo-reactor. The peak of 
MB as monitored by a UV1800, Shimadzu Co., Japan spectrophotometer until the desired exposure fluence was reached. $\mathrm{H}_{2} \mathrm{SO}_{4}$ and $\mathrm{NaOH}$ were used to adjust the initial $\mathrm{pH}$ before the degradation runs. The UV-vis spectrophotometer was used to carry out the on line analysis of the absorbing species at pre-selected time intervals of $0.5 \mathrm{~min}$. The samples were collected for further analysis (e.g., methanol) and analyzed by gas chromatography in the flame ionization detector.

Uridine $(0.12 \mathrm{mM})$ [40] and methanol $(0.1 \mathrm{mM})$ [41] were both used in the actinometry for the determination of the UV fluence (FUV) as a function of time. Details are described in Supplementary material S2. In the VUV/UV tube, methanol could measure the VUV $(185 \mathrm{~nm})$ fluence directly, since its UV photolysis (at $254 \mathrm{~nm}$ ) was low (Supplementary material S3). Therefore, the total fluence in the VUV/UV tube was similar to the sum of FUV and FVUV, since $99 \%$ of the VUV/UV mercury emission lines in the UV region were at $254 \mathrm{~nm}$ and at $185 \mathrm{~nm}$. Likewise, the total fluence in the UV tube was approximately equal to FUV, since the $185 \mathrm{~nm}$ photons were completely absorbed by the $\mathrm{TiO}_{2}$-doped tube wall. In addition, in the VUV/UV tube, the exposed fluence ratio of UV (254 nm) to VUV $(185 \mathrm{~nm})$ was determined to be 9.2 , which was similar to the ratio provided by the manufacturer of the low pressure (LP) mercury lamps.

\section{Results and discussion}

\subsection{Basic considerations on photo-Fenton mediated reactions activated by UV and VUV light leading to MB degradation}

Fig. 2a shows the MB degradation by VUV/UV, UV/UV photoFenton and UV photo-Fenton processes at an initial $\mathrm{pH}$ 3.3. The VUV/UV in the absence of $\mathrm{H}_{2} \mathrm{O}_{2}$ discolors the $\mathrm{MB}$ due to the radicals derived from the air $\left(\mathrm{O}_{2}\right)$ present [28-35]. Eqs. (7)-(8) also show that $\mathrm{OH}$-radicals generated by water photolysis may also intervene in $\mathrm{MB}$-degradation. The contribution of $\mathrm{H}_{2} \mathrm{O}_{2}$ will under irradiation by the $185 / 254 \mathrm{~nm}$ mercury resonance lines be higher compared to the $185 \mathrm{~nm}$ mercury resonance-line. But the light absorbed by $\mathrm{H}_{2} \mathrm{O}_{2}$ in the UV and VUV/UV region is too small to have an important effect on $\mathrm{MB}$ degradation at the very low $\mathrm{H}_{2} \mathrm{O}_{2}$ concentrations of $0.147 \mathrm{mM}$ used in this study. The low molar absorption coefficients $\mathrm{H}_{2} \mathrm{O}_{2}$, low $\mathrm{H}_{2} \mathrm{O}_{2}$ concentrations and the low photonic fluence associated with both mercury resonance lines may be responsible for this. The $\mathrm{H}_{2} \mathrm{O}_{2}$ decomposition under light irradiation in the UV-region is shown by Eq. (9) [22-24].

$\mathrm{H}_{2} \mathrm{O}_{2}+h v \rightarrow 2 \bullet \mathrm{OH} \Phi=2.0$

Photo-Fenton $\mathrm{UV} / \mathrm{H}_{2} \mathrm{O}_{2} / \mathrm{Fe}^{3+}$ reactions led to a complete $\mathrm{MB}$ degradation within about 8 min under UV light as shown Fig. 2a. The photochemical behavior of the Fe(III)-aqua hydroxy-complexes plays a determining role in the Fe-aqua complex absorption $[36,42,43]$. The $\mathrm{pH}$ and molar extinction coefficient of these Fe-aqua complexes play a determinant role in the photo-Fenton reactions mentioned before Eqs. (1)-(6). At pH above 3, the $\mathrm{Fe}\left(\mathrm{H}_{2} \mathrm{O}\right)_{6}{ }^{3+}$ is transformed into $\mathrm{Fe}(\mathrm{III}) \mathrm{OH}\left(\mathrm{H}_{2} \mathrm{O}\right)_{5}{ }^{2+}$, which is able to undergo ligand-to-metal-charge-transfer (LMCT). This treaction depends on the excitation wavelength and involves an inner sphere photoinduced electron transfer (LCMT) leading to Fe(II)-aqua complex and $\bullet \mathrm{OH}$ radicals through the reaction [44].

$\mathrm{Fe}(\mathrm{III}) \mathrm{OH}\left(\mathrm{H}_{2} \mathrm{O}\right)_{5}{ }^{2+}+\mathrm{H}_{2} \mathrm{O}+h v \rightarrow \mathrm{Fe}(\mathrm{II})\left(\mathrm{H}_{2} \mathrm{O}\right)_{6}{ }^{2+}+\cdot{ }^{\bullet} \mathrm{OH}$

When $\mathrm{H}_{2} \mathrm{O}_{2}$ is added to the MB solution under UV and VUV/UV light as shown in Fig. 2a, the higher efficiency of MB degradation can be explained by the $\mathrm{Fe}(\mathrm{II}) / \mathrm{Fe}$ (III) inter-conversion due to the MB-radicals produced during the MB degradation. This leads to an increased $\bullet \mathrm{OH}$-radicai production $[15,45]$. The experiments

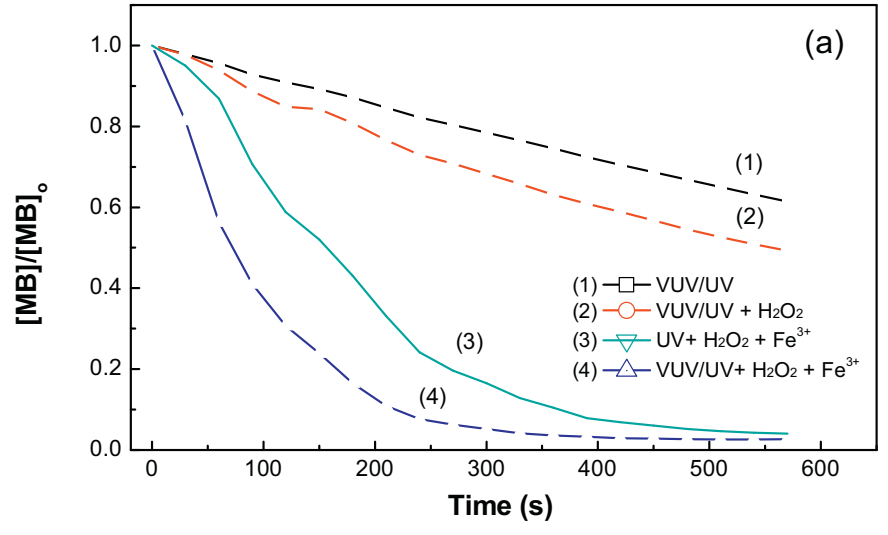

\begin{tabular}{|c|c|c|c|c|c|c|c|c|}
\hline 0 & 20 & 40 & 60 & 80 & 100 & 120 & 140 & 160 \\
\hline
\end{tabular}

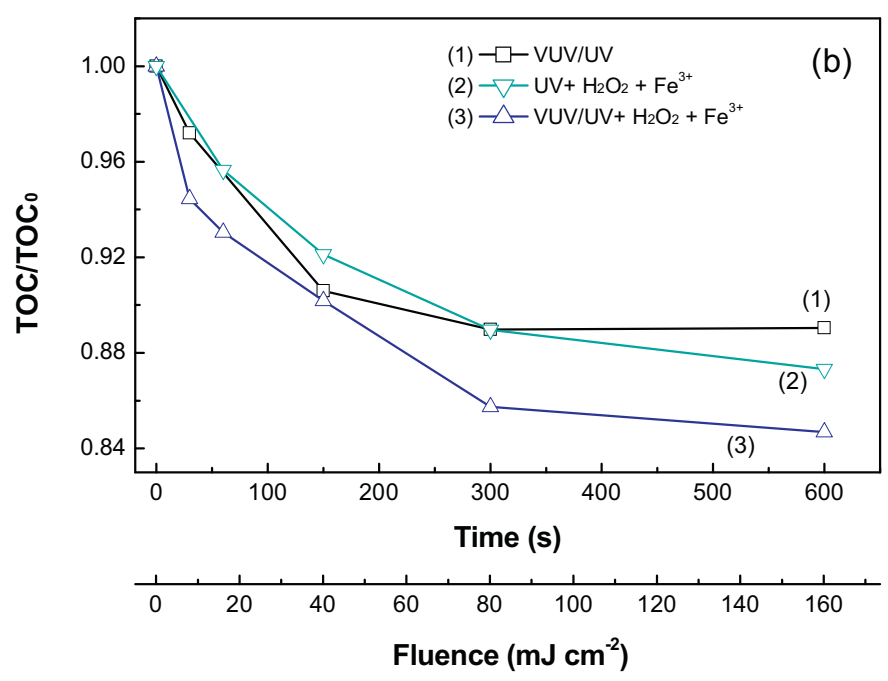

Fig. 2. Methylene blue (MB) degradation (a) and TOC reduction (b) in different photo-Fenton processes. Conditions: $[\mathrm{MB}]_{0}=0.016 \mathrm{mM},\left[\mathrm{H}_{2} \mathrm{O}_{2}\right]_{0}=0.147 \mathrm{mM}$, $\left[\mathrm{Fe}^{3+}\right]_{0}=0.05 \mathrm{mM}$, and $\mathrm{pH}_{0}$ 3.3. (For interpretation of the references to colour in this figure legend, the reader is referred to the web version of this article.)

reported in Fig. 2a have been carried out in the presence of air $\left(\mathrm{O}_{2}\right)$. The $\mathrm{Fe}(\mathrm{III}) \mathrm{OH}\left(\mathrm{H}_{2} \mathrm{O}\right)_{5}{ }^{2+}$ reacts with the $\mathrm{O}_{2}$ in the photo-reactor leading to $\mathrm{O}_{2}^{-}$- radicals enhancing further $\mathrm{MB}$ degradation since $\mathrm{O}_{2}$ has been shown to be favorable $[46,47]$ to Fenton/Photo-Fenton reactions.

Fig. 2b presents the mineralization of the MB under different experimental conditions up to $10 \mathrm{~min}$. It is readily seen that the MB-mineralization to $\mathrm{CO}_{2}$ attains only $\sim 15 \%$ after $10 \mathrm{~min}$. This suggests that the MB degradation (Fig. 2a) lead mainly to long-lived intermediates. These results agree with results reported earlier by Herrmann during the photocatalytic discoloration of $\mathrm{MB}$ on $\mathrm{TiO}_{2}$ [48].

\subsection{Effects of the solution components on the kinetics of $M B$ degradation: mechanistic considerations}

\subsubsection{MB degradation induced by VUV/UV and UV light}

Fig. 3a shows the MB degradation as a function of the initial dye concentrations from 0.0031 to $0.062 \mathrm{mM}$. The results demonstrate that high concentrations of MB slow down the degradation kinetics, due to the competition for the limited number of oxidative radicals in solution. MB degradation will also be induced by the direct photolysis by light at $185 / 254 \mathrm{~nm}$ as shown previously in Fig. 2 a. Table 1 shows that in the reaction solution $\left([\mathrm{MB}]_{0}=0.016 \mathrm{mM}\right.$, 

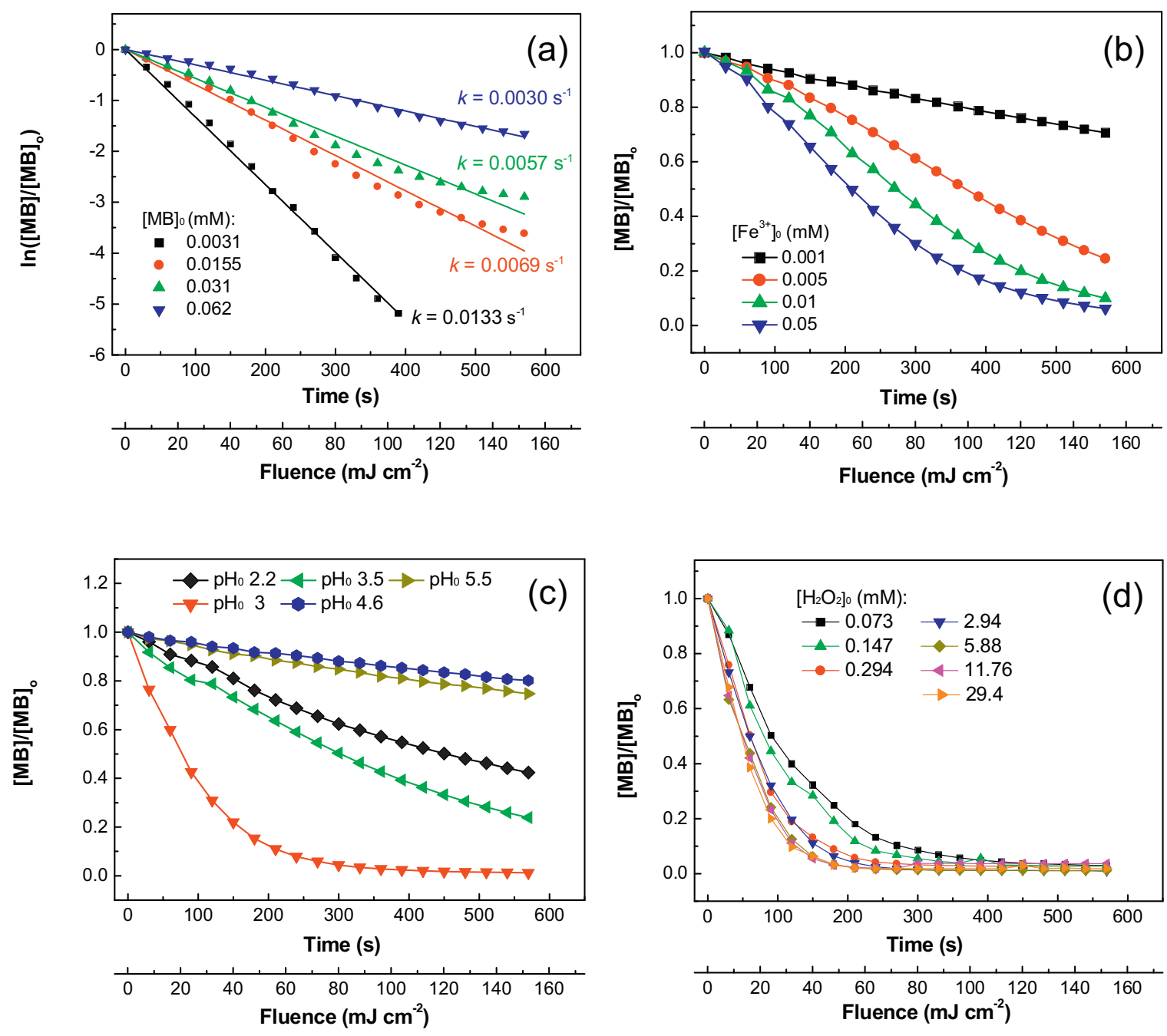

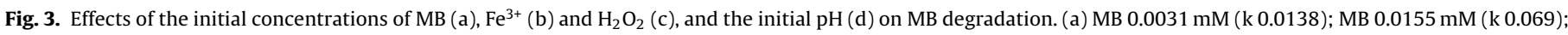
MB mM 0.031 (0.0057); MB mM 0.062 (0.0030).

$\left.\left[\mathrm{H}_{2} \mathrm{O}_{2}\right]_{0}=0.147 \mathrm{mM},\left[\mathrm{Fe}^{3+}\right]_{0}=0.05 \mathrm{mM}\right)$, the photons absorbed by MB from the $185 \mathrm{~nm}$ light amounted to $5 \%$ and $29.8 \%$ from the $254 \mathrm{~nm}$ second resonance line. The overall MB degradation under VUV/UV light involves the redox reaction shown below in Eq. (11). The initial photo-induced $\mathrm{MB} \bullet$ formation is followed by its decomposition within short times $[4,10,24,50]$. For this reason we address in section 3.3 the scavenging of the ${ }^{\bullet} \mathrm{OH} / \mathrm{HO}_{2}{ }^{\bullet}$ radicals, to sort out the participation of these highly oxidative radicals during $\mathrm{MB}$ degradation.

$$
\begin{aligned}
\mathrm{MB} & +\left[\mathrm{Fe}(\mathrm{III}) \mathrm{OH}\left(\mathrm{H}_{2} \mathrm{O}\right)_{5}{ }^{2+}\right]+\mathrm{H}_{2} \mathrm{O}+\mathrm{O}_{2}+\mathrm{H}^{+}+h v \\
& \rightarrow\left[\mathrm{MB} />\ldots . \mathrm{Fe}(\mathrm{II})\left(\mathrm{H}_{2} \mathrm{O}\right)_{6}{ }^{2+}\right]+\cdot \mathrm{OH}+\mathrm{MB}^{+}+\mathrm{HO}_{2}{ }^{-}
\end{aligned}
$$

The $\mathrm{MB}^{\bullet}$ excited state has been reported to be a singlet with a lifetime of $358 \mathrm{ps}$ intercrossing subsequently to the triplet state with a lifetime of $4.5 \mathrm{~ms}[48,49]$. A diluted MB aqueous solution contains an $\mathrm{O}_{2}$ concentration is $0.5 \times 10^{-3} \mathrm{M}$. The probability of the triplet $\mathrm{MB}^{\bullet}$ deactivation has been reported to be 0.04 [50]. The probability for the collision-controlled deactivation of $\mathrm{MB}^{\bullet}$ by $\mathrm{O}_{2}$ has been reported to be 0.53 [50]. The mechanism of the light induced MB degradation has been extensively reported and will not be discussed further in this study [51,52].

\subsubsection{Effect of the Fe-ions optical band absorption added in solution}

The runs reported in Fig. $3 \mathrm{~b}$ were carried out at $\mathrm{pH}$ 3.3. At this $\mathrm{pH}$ the short-hand notation of the predominating species is

Table 1

\begin{tabular}{|c|c|c|c|c|c|c|c|}
\hline Reactant & $\mathrm{C}(\mathrm{mM})$ & $\varepsilon_{254}\left(\mathrm{M}^{-1} \mathrm{~cm}^{-1}\right)$ & $\varepsilon_{185}\left(\mathrm{M}^{-1} \mathrm{~cm}^{-1}\right)$ & $A_{254}$ & $A_{185}$ & $P_{254}(\%)$ & $P_{185}(\%)$ \\
\hline $\mathrm{H}_{2} \mathrm{O}$ & 55.56 & 0.01 & 10 & 0.010 & 0.360 & 16.8 & 78.3 \\
\hline $\mathrm{H}_{2} \mathrm{O}_{2}$ & 0.147 & 19 & 341 & 0.001 & 0.010 & 0.9 & 2.2 \\
\hline $\mathrm{FeCl}_{3}$ & 0.05 & 3140 & 7250 & 0.031 & 0.073 & 52.6 & 15.8 \\
\hline MB & 0.016 & 5562 & 7229 & 0.018 & 0.023 & 29.8 & 5.0 \\
\hline Total & & & & & & 100 & 100 \\
\hline
\end{tabular}

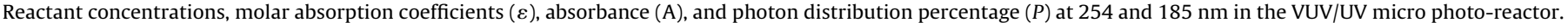


$\mathrm{Fe}(\mathrm{III})(\mathrm{OH})^{2+}[42]$. The complete species is noted as $\mathrm{Fe}\left(\mathrm{H}_{2} \mathrm{O}\right)_{5} \mathrm{OH}^{2+}$. Under light irradiation, this complex undergoes redox reactions leading to $\bullet \mathrm{OH}$-radicals $[11,53,54]$ :

$\mathrm{Fe}(\mathrm{III})(\mathrm{OH})^{2+}+h v \rightarrow \mathrm{Fe}(\mathrm{II})+\cdot \mathrm{OH}$

The most favorable MB photo-induced degradation was observed adding a concentration of $0.05 \mathrm{mM} \mathrm{Fe}^{3+}$ by Fig. 3b. The addition of $\mathrm{Fe}^{3+}$ to the MB-solution lead to a faster MB-degradation kinetics since more radicals are formed when more $\mathrm{Fe}(\mathrm{III})$ is present. The enhanced $\mathrm{H}_{2} \mathrm{O}_{2}$ decomposition has been reported due to the increased concentration of the $\mathrm{Fe}(\mathrm{III})$-OO- species in solution $[55,56]$. The Supplementary material S4 provides information about the spectra of a $0.016 \mathrm{mM}$ MB solution in the presence and absence of $\mathrm{FeCl}_{3}$. This last reagent was used as the source of Fe-ions during this study. The $\mathrm{Cl}^{-}$anions have a coordinating ability and will substitute water in the first coordination sphere of $\left[\mathrm{Fe}(\mathrm{III}) \mathrm{OH}\left(\mathrm{H}_{2} \mathrm{O}\right)_{5}{ }^{2+}\right]$ yielding mixed ligand complexes such as $\mathrm{Fe}\left(\mathrm{H}_{2} \mathrm{O}\right)_{5} \mathrm{Cl}^{2+}$ and $\mathrm{Fe}\left(\mathrm{H}_{2} \mathrm{O}\right)_{4} \mathrm{Cl}^{2+}[57,58]$.

\subsubsection{Effect of $p H$ on the aqueous solution under VUV irradiation}

The degradation of MB by VUV photo-Fenton processes at various pH's is shown in Fig. 3c. The kinetics presented in Fig. 3c confirms that the full hydrated $\mathrm{Fe}^{3+}$-ion, $\mathrm{Fe}\left(\mathrm{H}_{2} \mathrm{O}\right)_{6}{ }^{3+}$ is the most active catalytic species leading to the fastest $\mathrm{MB}$ degradation. When this aqua-metal complex gets de-protonated at $\mathrm{pH}<3$, it slows down the $\mathrm{MB}$ decomposition kinetics. At $\mathrm{pH}>3$ due, the formation of hydroxylated Fe-complexes up to $\mathrm{pH} 4.6$ also slow down the $\mathrm{MB}$ degradation. At $\mathrm{pH} \sim 4.6$ the $\mathrm{Fe}(\mathrm{OH})_{3}$ precipitates, and slows down the degradation of MB. But the slow MB-degradation involves hydrated Fe-hydroxide species present on the surface of the $\mathrm{Fe}(\mathrm{OH})_{3}$ precipitate.

\subsubsection{Effect of the added $\mathrm{H}_{2} \mathrm{O}_{2}$ concentration}

The MB degradation kinetics in Fig. 3d is shown to be almost insensitive to the concentration of $\mathrm{H}_{2} \mathrm{O}_{2}$ added in solution. The $\mathrm{MB}$ degradation rate increased slightly upon $\mathrm{H}_{2} \mathrm{O}_{2}$ addition from 0.073 to $5.88 \mathrm{mM}$ under VUV in a solution with an initial pH 3.3. At $\mathrm{H}_{2} \mathrm{O}_{2}$ concentrations between the 5.88 and $29.4 \mathrm{mM}$, the MB degradation was seen to be independent of the added $\mathrm{H}_{2} \mathrm{O}_{2}$. The excessive $\mathrm{H}_{2} \mathrm{O}_{2}$ added in solutionscavenged the ${ }^{\circ} \mathrm{OH}$ radical in solution [4,5]. During photo-Fenton reactions, the oxidation of $\mathrm{Fe}^{2+}$ to $\mathrm{Fe}^{3+}$ with a concomitant evolution of $\mathrm{O}_{2}$ has been reported [21]. Eq. (13) shows the redox processes in which $\mathrm{H}_{2} \mathrm{O}_{2}$ is oxidized to $\mathrm{O}_{2}$ trough a $\mathrm{FeO}^{2+}$ intermediate, occurs concomitantly with the $\mathrm{FeO}^{2+}$ species reacting with $\mathrm{Fe}^{2+}$ reducing $\mathrm{H}_{2} \mathrm{O}_{2}$ to $\mathrm{OH}^{-}$

$$
\mathrm{Fe}^{2+}+\mathrm{H}_{2} \mathrm{O}_{2} \rightleftharpoons\left(\mathrm{Fe}^{2+} \cdot \mathrm{H}_{2} \mathrm{O}_{2}\right) \stackrel{-\mathrm{H}_{\mathrm{O}} \mathrm{O}}{\longrightarrow} \mathrm{FeO}^{2+} \stackrel{\mathrm{x}^{\mathrm{O} \%}>\mathrm{Fe}^{2+}+\mathrm{O}_{2}+\mathrm{H}_{2} \mathrm{O}}{\stackrel{\mathrm{O}_{2}}{\longrightarrow} 2 \mathrm{Fe}^{3+}+2 \mathrm{OH}^{-}}
$$

\subsection{Scavenging of the main species leading to MB degradation}

Fig. 4a shows the MB degradation for a solution by adding various concentration of tert-butanol (TBA). A reaction rate of $1.9 \times 109$ has been reported for the reaction of TBA with the $\bullet \mathrm{OH}$-radicals as determined by competition kinetics [37,44]. Fig. 4a shows that an increasing the concentration of TBA from $1 \mathrm{mM}$ to $10 \mathrm{mM}$, led to a $\mathrm{MB}$ degradation decreased due to the quenching of the $\bullet \mathrm{OH}^{\circ}$ radicals by TBA $[4,10,19]$.

Fig. $4 \mathrm{~b}$ reports the $\mathrm{MB}$-degradation in solution in the presence of benzoquinone (BQ), a well-known superoxide radical quencher via fast electron transfer [59-61]. Fig. 4b shows that the degradation of MB was completely inhibited by $1 \mathrm{mM} B \mathrm{BQ}$. This shows the most active species intervening in $\mathrm{MB}$ degradation is $\mathrm{HO}_{2}{ }^{\circ}$. BQ scav-
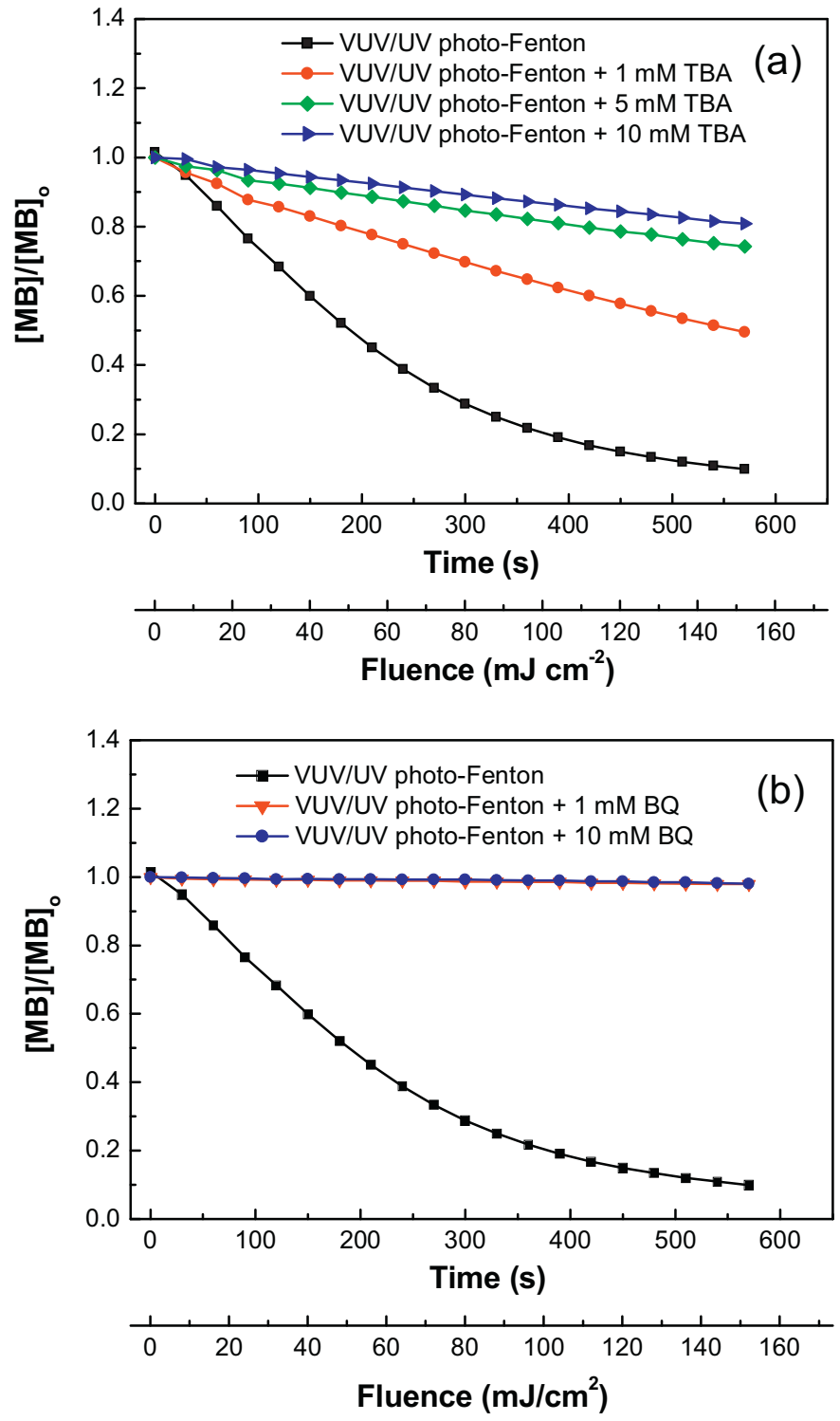

Fig. 4. $M B$ degradation in the presence and absence of tert-butanol (TBA) (a) and benzoquinone (BQ) (b) under VUV/UV light irradiation. Conditions: $[\mathrm{MB}]_{0}=0.016 \mathrm{mM},\left[\mathrm{H}_{2} \mathrm{O}_{2}\right]_{0}=0.147 \mathrm{mM},\left[\mathrm{Fe}^{3+}\right]_{0}=0.05 \mathrm{mM}$, and $\mathrm{pH}_{0}=3.3$.

enges the $\mathrm{HO}_{2} \bullet$ radicals with a bimolecular rate of $9.6 \times 10^{8} \mathrm{M}^{-1} \mathrm{~s}^{-1}$ leading to the formation of $\mathrm{O}_{2}$ noted below in Eq. (14) [61]:

$\mathrm{BQ}+\mathrm{HO}_{2}^{\bullet} \rightarrow \mathrm{BQ}^{-\bullet}+\mathrm{H}^{+}+\mathrm{O}_{2}$

The $\mathrm{HO}_{2} \bullet$ radicals disproportionate at $\mathrm{pH}>4.8$ as shown in Eq. (15):

$\mathrm{HO}_{2}^{\bullet} \Leftrightarrow \mathrm{H}^{+}+\mathrm{O}_{2}^{-\bullet} \mathrm{p} K_{\mathrm{a}}=4.8$

Estimation of the $\cdot \mathrm{OH}$ radical lifetime takes into account the rate of the reaction $\mathrm{Fe}^{2+}+\mathrm{H}_{2} \mathrm{O}_{2} \rightarrow \mathrm{Fe}^{3+}+\mathrm{OH}^{-+}+\mathrm{OH}^{-}$ $\left(k_{1}=40-60 \mathrm{M}^{-1} \mathrm{~s}^{-1}\right)$ and also of the reaction of $\bullet \mathrm{OH}+\mathrm{MB}$ $(\mathrm{RH}) \rightarrow$ products $\left(k_{2} \sim 10^{10} \mathrm{M}^{-1} \mathrm{~s}^{-1}\right)$. Inserting the solution parameters $\mathrm{MB}=0.016 \mathrm{mM}, \mathrm{H}_{2} \mathrm{O}_{2}=0.147 \mathrm{mM}, \mathrm{Fe}^{3+}=0.05 \mathrm{mM}$ in the quasi-stationary state for ${ }^{\bullet} \mathrm{OH}$ concentration and approximating the radical concentration to zero (since it is almost negligible), renders a lifetime for the $\bullet \mathrm{OH}$ radical $\sim 2$ ns (see Supplementary material S4).

To estimate the $\mathrm{HO}_{2}{ }^{\bullet}$ radical lifetime, the Eqs: $\mathrm{Fe}^{2+}+\mathrm{HO}_{2}^{\bullet} \rightarrow \mathrm{Fe}^{3+}+\mathrm{HO}_{2}^{-\bullet}, \quad k_{3}=8 \times 10^{5} \mathrm{M}^{-1} \mathrm{~s}^{-1} \quad$ [15] and $\mathrm{HO}_{2}{ }^{\bullet}+\mathrm{RH}(\mathrm{MB}) \rightarrow$ product $k_{4} \sim 1.2 \times 10^{6} \mathrm{M}^{-1} \mathrm{~s}^{-1}$ were considered 


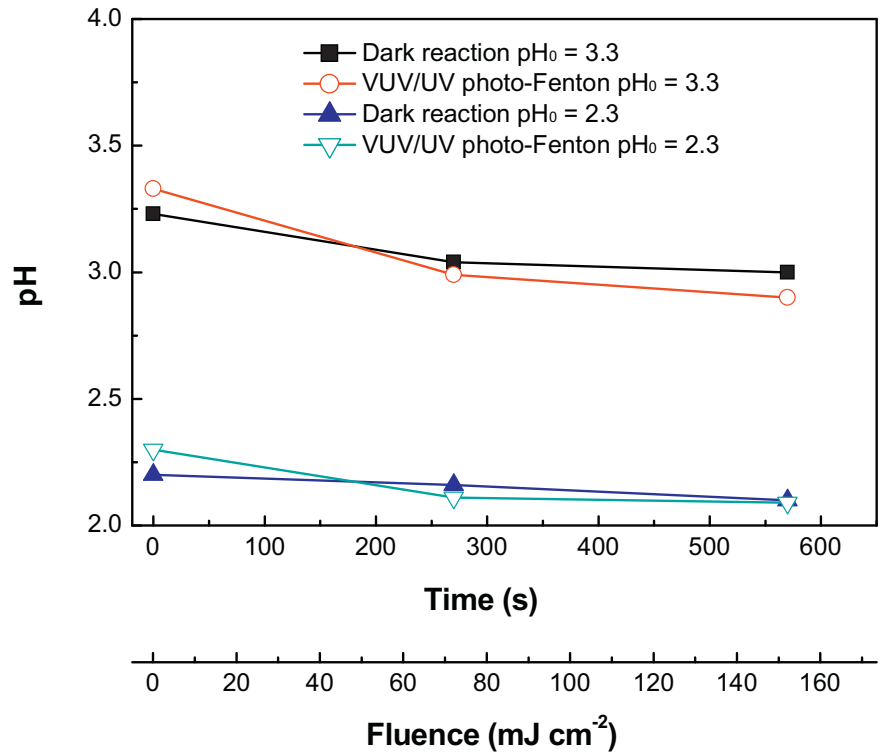

Fig. 5. $\mathrm{pH}$ variations during the VUV/UV photo-Fenton and dark-Fenton processes at initial $\mathrm{pH}$ values of 2.3 and 3.3. Conditions: $[\mathrm{MB}]_{0}=0.016 \mathrm{mM},\left[\mathrm{H}_{2} \mathrm{O}_{2}\right]_{0}=0.147 \mathrm{mM}$, $\left[\mathrm{Fe}^{3+}\right]_{0}=0.05 \mathrm{mM}$.

and allows to estimate a lifetime of $0.38 \mathrm{~s}$ for the $\mathrm{HO}_{2} \cdot$ radical. The $\mathrm{OH} / \mathrm{OH}-$ potential $1.90 \mathrm{eV}[62]$ is higher than the potential of $\cdot \mathrm{HO}_{2} / \mathrm{HO}_{2}{ }^{-}$of $0.75 \mathrm{eV}$ [63-65]. The Smoluchowski simplified approximation was used to calculate the mean-free path of the $\cdot \mathrm{OH}, \mathrm{x}_{2} \cong \mathrm{D}_{\mathrm{T}}$ where $\mathrm{D}$ is the diffusion of molecules with a low molecular weight and $\mathrm{T}$ is the inverse of the pair $\mathrm{MB}+{ }^{\bullet} \mathrm{OH}$ lifetime. Inserting the inverse of the reaction rate $10^{10} \mathrm{M}^{-1} \mathrm{~s}^{-1}$ and the MB concentration (i.e., $0.016 \times 10^{-3} \mathrm{M}$ ) a mean-free path $\mathrm{x} \cong 52 \mathrm{~nm}$ can be estimated for $\bullet \mathrm{OH}$. By the same approach, a mean-free path for the $\mathrm{HO}_{2}{ }^{\bullet}$ radicals of about $580 \mu$ was estimated (see S6). The data in Fig. 4a and b, to suggest that the MB degradation is not controlled by the radical redox-potentials but by the radical lifetimes and mean-free diffusion distances.

\section{4. $\mathrm{PH}$ shift and $\mathrm{pH}$ dependent intervention of the $\mathrm{HO}_{2} \bullet$ radical during $M B$ degradation}

Fig. 5 shows that for a solution $([\mathrm{MB}]=0.016 \mathrm{mM}$, $\left[\mathrm{H}_{2} \mathrm{O}_{2}\right]=0.147 \mathrm{mM},[\mathrm{Fe} 3+]=0.05 \mathrm{mM}$, at an initial $\mathrm{pH}=3.3$, the $\mathrm{pH}$ moves to more acidic values in the dark and under VUV/UV irradiation during MB degradation as suggested in Eq. (16). The $\mathrm{pH}$ shift in the solution under VUV/UV from 3.3 to 2.8 shown in Fig. 5 corresponds to a fourfold increase in the $\mathrm{H}^{+}$concentration in solution. This $\mathrm{pH}$ shift is due to: (a) the $\mathrm{MB}^{+}$acid-cation generation noted in Eq. (11), and (b) the build up of short carboxylic long-lived acid intermediates in solution containing $\mathrm{COOH}$ groups with $\mathrm{pK}_{\mathrm{a}}$ values $\sim 3.0$ as reported by Herrmann et al. [48]. The shift to more acid values during the MB-degradation time is suggested in Eq. (16)

(16) $\mathrm{MB}^{\bullet}+\mathrm{Fe}^{3+}+\mathrm{H}_{2} \mathrm{O} \rightarrow \mathrm{MB}-\mathrm{OH}+\mathrm{H}^{+}+\mathrm{Fe}^{2+}$

Fig. 6 shows MB degradation by VUV/UV/ $\mathrm{H}_{2} \mathrm{O}_{2}\left(\mathrm{H}_{2} \mathrm{O}_{2} 0.147 \mathrm{mM}\right)$ process in the presence and absence of $\mathrm{BQ}$ at $\mathrm{pH}$ values of 3.3 and 5.4. In the dark (full points) BQ did not preclude MB-degradation since no radicals were produced. This is not surprising due to the fact that the oxidation of organic compounds by $\mathrm{H}_{2} \mathrm{O}_{2}$ in the dark have been reported to be independent of $\mathrm{pH}[66,67]$. But under VUV/UV light, the $\mathrm{H}_{2} \mathrm{O}_{2}$ at $\mathrm{pH} 3.3$ leads to $\mathrm{HO}_{2}$. In this case Fig. 6 shows that only about $12 \% \mathrm{MB}$ was degraded within $10 \mathrm{~min}$. The data at $\mathrm{pH} 5.4$ for light activated MB-degradation shows that no MB degradation was observed at this $\mathrm{pH}$. The reason for this

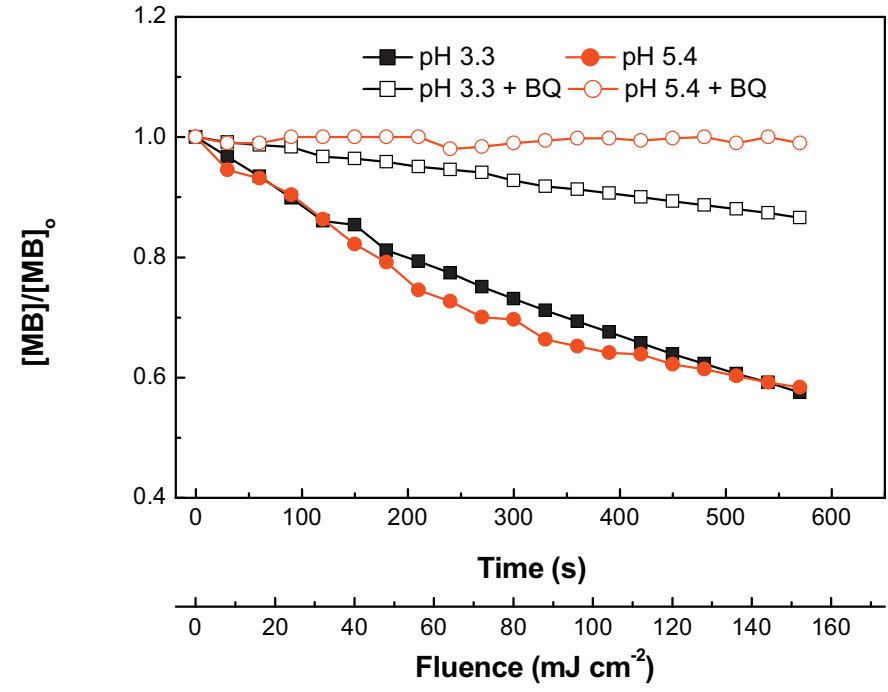

Fig. 6. $M B$ degradation by VUV/UV/ $/ \mathrm{H}_{2} \mathrm{O}_{2}$ in the presence and absence of $\mathrm{BQ}$ at initia $\mathrm{pH}$ values of 3.3 and 5.4. Conditions: $[\mathrm{MB}]_{0}=0.016 \mathrm{mM},\left[\mathrm{H}_{2} \mathrm{O}_{2}\right]_{0}=0.147 \mathrm{mM}$.

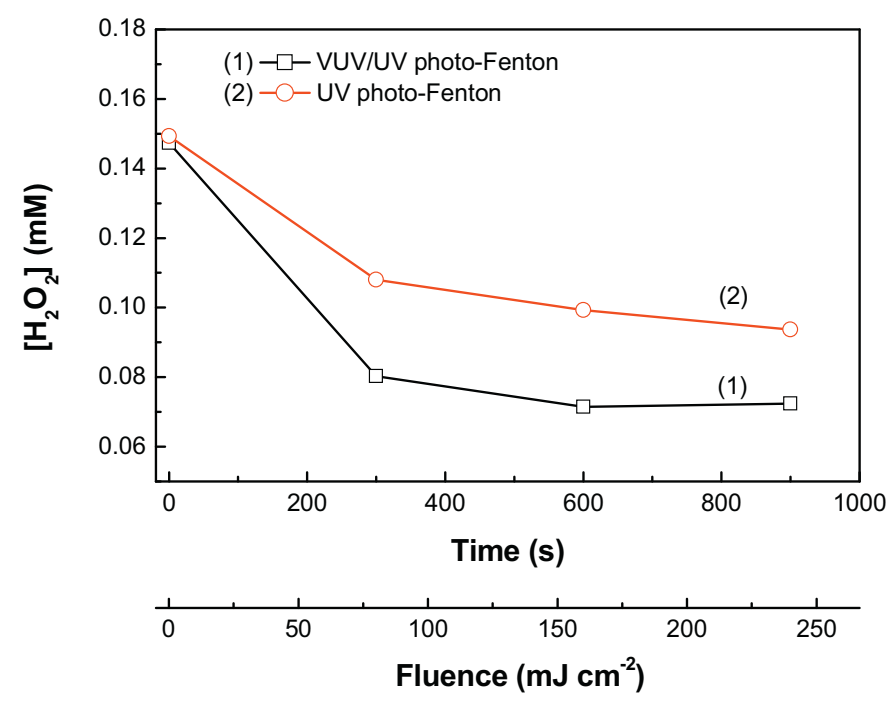

Fig. 7. Change of $\mathrm{H}_{2} \mathrm{O}_{2}$ concentration with reaction time during the VUV/UV and UV photo-Fenton processes. Conditions: $[\mathrm{MB}]_{0}=0.016 \mathrm{mM},\left[\mathrm{H}_{2} \mathrm{O}_{2}\right]_{0}=0.147 \mathrm{mM}$, $\left[\mathrm{Fe}^{3+}\right]_{0}=0.05 \mathrm{mM}$, and $\mathrm{pH}_{0} 3.3$.

observation is that at $\mathrm{pH} 5.4$, the $\mathrm{HO}_{2} \cdot$ radicals disproportionate to $\mathrm{O}_{2}^{-\bullet}$ as shown previously in Eq. (15).

\section{5. $\mathrm{H}_{2} \mathrm{O}_{2}$ consumption during $\mathrm{MB}$ degradation as a function of the applied light}

Fig. 7 shows the decrease of the initial concentration of $\mathrm{H}_{2} \mathrm{O}_{2}$ during VUV/UV photo-Fenton and UV photo-Fenton processes. The former shows a more rapid decrease of $\mathrm{H}_{2} \mathrm{O}_{2}$ concentration, due to the higher light dose. The $\mathrm{H}_{2} \mathrm{O}_{2}$ decrease in UV photo-Fenton process is slower when applying only $254 \mathrm{~nm}$ light because the molar

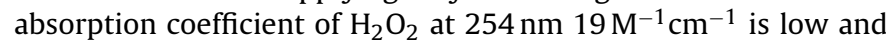
the fluence is also not high $\left(300 \mathrm{~mJ} \mathrm{~cm}^{-2}\right)$.

Generation of $\mathrm{H}_{2} \mathrm{O}_{2}$ during VUV/UV photolysis has been reported in the presence of dissolved $\mathrm{O}_{2}$ and organic compounds in solution $[30,34,35]$. The mechanism involves $\mathrm{H}^{\bullet}$ trapping by $\mathrm{O}_{2}$ yielding $\mathrm{HO}_{2} \cdot$. These radicals subsequently recombine to yield $\mathrm{H}_{2} \mathrm{O}_{2}$. About $0.025 \mathrm{mM} \mathrm{H} \mathrm{H}_{2}$ was generated in pure $\mathrm{H}_{2} \mathrm{O}$ under VUV/UV (see Supplementary material S7). However, during the MB 
degradation by VUV/UV photo-Fenton the amount of $\mathrm{H}_{2} \mathrm{O}_{2}$ generated by VUV/UV is much lower compared to the added initial $\mathrm{H}_{2} \mathrm{O}_{2}$ concentration of $0.147 \mathrm{mM}$.

\section{Conclusions}

The discoloration/degradation of $\mathrm{MB}$ by the Fenton reagent was enhanced by VUV/UV and UV irradiation from low-pressure mercury lamps. The effects of the initial $\mathrm{MB}, \mathrm{Fe}^{3+}$ and $\mathrm{H}_{2} \mathrm{O}_{2}$ concentrations were evaluated as well as the effect of the initial $\mathrm{pH}$ during the $\mathrm{MB}$ degradation. The effect of the $\mathrm{HO}_{2}$-radical scavenging at different $\mathrm{pH}$ and their effect on the MB degradation kinetics was discussed. Appropriate radical scavengers identified the main oxidative radicals leading to MB degradation. The radical lifetimes and their diffusion distances in aqueous solution were estimated. A simplified mechanism for the radical species leading to MB oxidation is suggested in this study.

\section{Acknowledgments}

This work was supported by: the National Natural Science Foundation of China (51408592) and Marie Curie/E.U. Seventh Program FP7/2007-2013 under the REA (Agreement No. 318926), the EPFL and COST MP1106.

\section{Appendix A. Supplementary data}

Supplementary data associated with this article can be found, in the online version, at http://dx.doi.org/10.1016/j.apcatb.2016. 01.014 .

\section{References}

[1] P. Vandevivere, R. Blanch, W. Verstratete, J. Chem Technol. Biotechnol. 72 (1988) 289-302.

[2] P. Gogate, A. Pandt, Adv. Environ. Res. 8 (2004) 501-551.

[3] T. Openlaender, Photochemical Purification of Water and Air, Wiley-VCH, Weinheim, Germany, 2003.

[4] A. Sychev, Russ. Chem. Rev. 64 (1995) 1105-1129.

[5] Chemical Water Treatment, Principles and Practice, in: H. Roques (Ed.), VCH Publishers Inc., New York 10010, NY, 1995.

[6] Y. Lee, L. Kovalova, C. McArdell, U. von Gunten, Water Res. 64 (2014) 134-148.

[7] N. Cheremisinoff, Handbook of Water and Wastewater Treatment Technologies, Elsevier Inc., 2002, 2016.

[8] Meng Chong, Bo Jin, Christopher Chow, Chris Saint, Water Res. 44 (2010) 2997-3027.

[9] S. Malato, P. Fernandez-Ibanez, I. Maldonado, J. Blanco, W. Gernjak, Catal. Today 147 (2009) 1-59.

[10] J. Schneider, M. Matsuoka, M. Takeuchi, J.L. Zhang, Yu Horiuchi, M. Anpo, D. Bahnemann, Chem. Rev. 114 (2014) 9919-9986.

[11] R. Bauer, G. Waldner, H. Fallmann, S. Hager, M. Klare, T. Krutzler, S. Malato, P. Maletzky, Catal. Today 53 (1999) 131-144

[12] R. Bauer, H. Fallmann, Res. Chem. Intermed. 23 (1997) 341-354.

[13] N. De la Cruz, L. Esquius, D. Grandjean, A. Magnet, A. Tungler, L.F. de Alencastro, C. Pulgarin, Water Res. 47 (2013) 5836-5845.

[14] D. Spuhler, J.-A. Rengifo-Herrera, C. Pulgarin, Appl. Catal. B: Environ. 96 (2010) 126-141.

[15] J. Kiwi, A. Lopez, V. Nadtochenko, Environ. Sci. Technol. 34 (2000) 2162-2168

[16] S. Parra, I. Guasaquillo, O. Enea, J. Kiwi J. Phys. Chem. B 107 (2003) 7026-7035.
[17] V. Nadtochenko, J. Kiwi Inorg. Chem. 37 (1998) 5233-5238.

[18] J. Fernandez, J. Bandara, A. Lopez, Ph. Buffat, J. Kiwi, Langmuir 15 (1999) 185-192.

[19] P. MacFaul, D. Wayner, K.U. Ingold, Acc. Chem. Res. 31 (1998) 159-162.

[20] C. Walling, J. Am. Chem. Soc. 8 (1975) 125-130.

[21] M. Kremer, J. Phys. Chem. A. 107 (2003) 1734-1741

[22] R. Chen, J. Pignatello, Environ. Sci. Technol. 31 (1997) 2399-2406.

[23] J.R. Bolton, C.E. Cotton, The Ultraviolet Disinfection Handbook, 1st edition, American Works Assoc, Denver Colorado, 2008.

[24] E. Legrini, E. Oliveiros, A.M. Braun, Chem. Rev. 93 (1993) 671-684

[25] K. Zoschke, H. Bornick, E. Worch, Water Res. 52 (2014) 131-145.

[26] A. Bozzi, T. Yuranova, J. Kiwi, J. Photochem. Photobiol. A 172 (2005) 27-34.

[27] T. Oppenlaender, Chem. Eng. Technol. 21 (1998) 502-505.

[28] M. Gonzales, E. Oliveiros, E. Woerner, A.M. Braun, J. Photochem. Photobiol. C 5 (2004) 225-246

[29] N. Quici, M. Litter, A.M. Braun, E. Oliveiros, J. Photochem. Photobiol. A 197 (2008) 306-312

[30] G. Imoberdorf, M. Mohseni, Chem. Eng. Sci. 66 (2011) 1159-1167.

[31] M. Satuf, R. Brandi, A.E. Cassano, O.M. Alfano, Appl. Cat. B. 82 (2008) 37-49.

[32] H. Glaze, Y. Lay, W. Kang, Indust. Chem. Eng. Res. 34 (1995) 2314-2323.

[33] J. Crittenden, S. Hu, W. Hand, A. Green, Water Res. 33 (1999) 2315-2328.

[34] S. Robl, M. Worner, D. Maier, A.M. Braun, Photochem. Photobiol. Sci. 11 (2012) 1041-1050.

[35] M. Bagheri, M. Mohseni, J. Hazard. Mater. 294 (2015) 1-8.

[36] P. Ciesla, P. Kocot, P. Mytiych, S. Stasicka, J. Mol. Catal. A 234 (2004) 17-33.

[37] M.K. Li, Z.M. Qiang, T.G. Li, J.R. Bolton, C.L. Liu, Environ. Sci. Technol. 45 (2011) 3034-3039.

[38] C. Duca, G. Imoberdorf, M. Mohseni, Photochem. Photobiol. 90 (2014) 238-240.

[39] D. Wang, T. Oppenlander, M.G. El-Din, J.R. Bolton, Photochem. Photobiol. 86 (2010) 176-181.

[40] N. Klamerth, S. Malato, A. Aguera, A. Fernandez-Alba, G. Mailhot, Environ. Sci. Technol. 46 (2012) 2885-2892.

[41] S. Jin, A. Mofidi, K.G. Linden, J. Environ. Eng. ASCE 132 (2006) 831-841.

[42] A. Safarzadeh, J.R. Bolton, S.R. Carter, J. Adv. Oxid. Technol. 1 (1996) 18-21.

[43] W. Feng, D. Nansheng, Chemosphere 41 (2000) 1137-1147.

[44] Y. Zuo, J. Hoigné, J. Environ. Sci. Technol. 26 (1992) 1014-1019.

[45] S. Bossmann, E. Oliveiros, S. Gob, S. Siegwart, E. Dahlen, L. Straub, M. Worner, A.M. Braun, J. Phys. Chem. 102 (1998) 5542-5551.

[46] B.M. Woelker, F.M. Morel, B. Sulzberger, Environ. Sci. Technol. 31 (1997) 1004-1010.

[47] R. Helz, G. Zepp, G. Crosby, Aquatic and Surface Chemistry, Lewis Pub, Boca Raton, Florida, 1994

[48] A. Houas, H. Lachheb, M. Ksibi, E. Elaloui, C. Guillard, J.M. Herrmann, Appl. Catal. B 31 (2001) 145-157.

[49] P.V. Kamat, Chem. Rev. 93 (2011) 267-300.

[50] S. Rtimi, C. Pulgarin, R. Sanjines, J. Kiwi, Appl. Catal. B 162 (2015) 236-244.

[51] A. Mills, J. Wang, J. Photochem. Photobiol. A 127 (1999) 123-134.

[52] A. Mills, Appl. Catal. B 128 (2012) 9144-9149.

[53] B.C. Faust, J. Hoigné, Atmos. Environ. 24A (1990) 79-89.

[54] J.H. Baxendale, J. Magee, J. Trans. Faraday Soc. 51 (1955) 205-212.

[55] D.T. Sawyer, C. Kang, A. Llobet, C. Redman, J. Am. Chem. Soc. 115 (1993) 5817-5818.

[56] H. Gallard, J. de Laat, Water Res. 34 (2000) 3107-3116.

[57] V. Balzani, V. Carassiti, Photochemistry of Coordination Compounds, Academic Press, London/NewYork, 1970 (145192).

[58] H. Balkenberg, P. Warneck, J. Phys. Chem. 99 (1995) 5214-5221.

[59] P. Piccinini, C. Minero, M. Vincentini, E. Pelizzetti, J. Chem. Soc. Faraday Trans. 93 (1997) 1993-2000.

[60] P. Wardman, J. Phys, Chem. Ref. Data 18 (1989) 1637-1755.

[61] R. Battino, L. Clever, Chem. Rev. 66 (1966) 395-413.

[62] M.D. Stanbury, Adv. Inorg. Chem. 33 (1989) 69-76.

[63] D. Dophin, B. James, Inorganic chemistry: towards the 21st century, ACS Symp. Ser. 211 (1982) 103-112.

[64] J.H. Merz, W.A. Waters, J. Chem. Soc. (1949) 2427-2434

[65] L.M. Dorfman, G.E. Adams, Reactivity of the OH-Radical in Aqueous Solutions, Report No NDRDS-NBS-46US Government Washington D.C. 1973.

[66] F. Haber, J. Weiss, Proc. R. Soc. 134 (1934) 332-351.

[67] D. Wang, J.R. Bolton, R. Hofmann, Water Res. 46 (2012) 4677-4686. 